\title{
ПРОДВИЖЕНИЕ БОЛЬШОГО ЕВРАЗИЙСКОГО ПАРТНЕРСТВА В РАМКАХ ЕАЭС: ПРОБЛЕМЫ И ПЕРСПЕКТИВЫ
}

\author{
А. В. ИВАНЦОВ \\ Академия Управления при Президенте РБ \\ Минск, Республика Беларусь
}

В данной статье рассматривается текущее состояние и дальнейшие перспективы интеграционных объединений, а также форматы многостороннего экономического сотрудничества с точки зрения реализации инициативы Большого евразийского партнерства. Автор анализирует опыт крупнейших многосторонних форматов в Евразии - Всеобъемлющего регионального экономического партнерства (ВРЭП), китайской инициативы «Один пояс - один путь», Евразийского экономического союза и др.

Автор делает вывод о том, что в нынешнем состоянии экономической сферы Большой Евразии наблюдается институциональная перегруженность, вызванная существованием ряда параллельно развивающихся интеграционных проектов и механизмов экономического сотрудничества. Усиление ЕАЭС как институционального центра Большой Евразии может стать базисом для формирования сбалансированного нормативного мега пространства. Однако совокупный экономический потенциал государств - участников ЕАЭС не позволяет Союзу быть крупнейшим экономическим полюсом и ведущим центром развития многосторонних институтов в Большой Евразии.

Предполагается, что решением в этой ситуации могло бы стать развитие Всеобъемлющего евразийского партнерства в сторону сопряжения ЕАЭС и ВРЭП - крупнейшего формата выработки правил международного экономического взаимодействия в Азии и формулирования конкретных предложений по выстраиванию системы взаимовыгодных отношений между крупнейшими игроками Евразии, в которую все заинтересованные государства будут вовлечены на взаимовыгодных условиях для укрепления международного сотрудничества.

Ключевые слова: Большое евразийское партнерство; ВРЭП; ЕАЭС; Евразия; интеграция; «Один пояс - один путь»; Союз; ЭПШП; ШОС.

Образец цитирования: Иванцов $A$. В. Продвижение Большого евразийского партнерства в рамках ЕАЭС: проблемы и перспективы // Актуальные проблемы международных отношений и глобального развития : сб. науч. статей. Минск, 2020. Вып. 8. С. 47-57. https://doi.org/10.33581/2311-947-2020-8-47-58 
Введение. На пространстве Евразии наблюдается появление мега региональных инициатив, выдвигаемых ведущими игроками континента. В 2011 году Госдепартамент США рассматривал концепцию «Нового шелкового пути», как попытку укрепления интеграции в области торговли и экономики между Афганистаном, Центральной Азией, Пакистаном и Индией, а шелковый путь Север-Юг «в качестве дополнения к связям Восток - Запад в Евразии» [2]. Свои инициативы такого рода есть у Китая - направленная на унификацию региональных усилий в сфере инфраструктурного строительства Инициатива Пояса и Пути, и у Японии - в виде инициированного кабинетом Синдзо Абэ «Партнерства в области создания качественной инфраструктуры» ${ }^{1}$.

Цель данной статьи - проанализировать перспективы создания Большого евразийского партнерства, выявить проблемы и обозначить перспективы дальнейшего формата взаимодействия.

Хронологические рамки исследования охватывают период со второй половины ХХ в. по настоящее время.

Методы исследования. При написании статьи были использованы методы исследования международных отношений, как контентанализ и ивент-анализ, а также исторический и описательный.

обзор литературы по теме. Главными источниками для анализа проблематики послужили работы, посвященные формированию евразийской интеграции, китайской инициативы «Один пояс - один путь», их роли и места в региональном сотрудничестве. Среди них можно назвать научные статьи М. Глянца, С.Ю. Глазьева, Д.П. Новикова, J. Nye, R. Keohane, K. Waltz и др.

Результаты исследования. Идея создания Большого Евразийского партнерства была сформулирована В.В. Путиным 3 декабря 2015 г. в ходе обращения с Посланием Федеральному Собранию Российской Федерации: «...Предлагаю вместе с коллегами по ЕАЭС начать диалог с членами ШОС и АCEAH, а также с государствами, которые присоединяются к ШОС, о создании возможного экономического партнёрства. Совместно наши государства составляют почти треть мировой экономики по паритету покупательной способности.

\footnotetext{
${ }^{1}$ Ministry of Foreign Affairs of Japan (2015) Announcement of "Partnership for Quality Infrastructure: Investment for Asia's Future”. 21 May. [Electronic resource]. URL: http://www.mofa.go.jp/ policy/oda/page18_000076.html (accessed 22.08.2020).
} 
Такое партнёрство на начальном этапе могло бы сконцентрироваться на вопросах защиты капиталовложений, оптимизации процедур движения товаров через границы, совместной выработки технических стандартов для продукции следующего технологического поколения, на взаимном открытии доступа на рынки услуг и капиталов. Естественно, что это партнёрство должно строиться на принципах равноправия и учёта взаимных интересов...»².

Большое евразийское партнерство (БЕП) представляет собой сеть диалогов между ключевыми игроками в Евразии, не только из числа крупнейших национальных экономик, но и региональных экономических объединений, включая неформальные образования и инициативы, такие как китайская инициатива «Один пояс - один путь» (ОПОП), Северный морской путь, Транссиб и т.д.

В научной литературе сложилось устойчивое мнение, нашедшее отражение как в либеральных теориях и концепциях, так и у многих авторов традиции реализма, о том, что создание и развитие институтов служит укреплению международной системы путем развития доверия между государствами [4], либо стабилизируя распределение сил и статусов внутри международных иерархий [5]. Особое внимание уделяется стимулирующей роли образовательных центров и норм в развитии экономических взаимосвязей между государствами и повышению взаимозависимости между ними, что позволяет говорить о преимущественно позитивной роли практически любого институционального строительства для укрепления политических и экономических связей между государствами.

На сегодняшний день в Евразии успешно работает полтора десятка региональных экономических объединений разного уровня глубины интеграции и масштаба охватываемых сфер регулирования. Только два из них - ЕС и ЕАЭС - имеют наднациональные органы регулирования, в то время как другие функционируют как межгосударственные. Большая часть региональных объединений нацелена на устранение торговых барьеров, формирование зон свободной торговли, гармонизацию норм технического, таможенного, тарифного и нетарифного регулирования. Однако на практике создание образова-

\footnotetext{
2 Путин призвал создать большое Евразийское партнерство. Петербургский международный экономический форум // Информационное агентство ТАСС [Электронный ресурс]. 2016. URL: http://tass.ru/pmef-2016/article/3376295 (дата доступа: 22.08.2020).
} 
тельных центров далеко не всегда ведет к преодолению противоречий между государствами и снижению транзакционных издержек при межгосударственном взаимодействии (прежде всего экономическом). Бурное развитие различных многосторонних форматов и институтов в Евразии в последние два десятилетия в настоящий момент является, скорее, источником конфликтов. Региональные форматы сотрудничества активно используются государствами для стабилизации окружающего их пространства - в условиях ослабления образовательных центров глобального регулирования. В существенной мере такая политика характерна для региональных игроков, претендующих на роль самостоятельных центров силы на фоне относительного ослабления глобального либерального порядка и его опорного государства в лице США, которые, как правило, и являются инициаторами создания таких форматов [4, pp. 82-96]. Однако среди конкуренции между крупными державами предлагаемые ими образовательные центры и форматы зачастую воспринимаются их оппонентами как враждебные. В последнее время ряд исследователей говорят даже о феномене «институционального оружия», позволяющего государствам использовать продвижение данных институтов и норм как инструмент международно-политической борьбы ${ }^{3}$.

Одновременно с базовыми региональными объединениями (таможенными союзами и зонами свободной торговли), сформированными для создания общих рынков товаров, труда и капитала, а также услуг действует ряд региональных инициатив, направленных на стимулирование инвестиционной активности, осуществление совместных инвестиционных проектов, включая крупномасштабные программы развития транспортной и энергетической инфраструктуры. Большую роль в поддержке таких интеграционных инициатив играют международные банки и институты развития, действующие как в рамках соответствующих региональных объединений, так и всего евразийского материка. При этом, отличительной чертой Большого Евразийского партнерства является возрастающая роль региональных интеграционных объединений Евразийского континента, таких как EАЭС, АСЕАН, ШОС, ЕС.

\footnotetext{
${ }^{3}$ Leonard Mark (2016). Connectivity Wars. [Electronic resource]. URL: http://www.ecfr.eu/page//Connectivity_Wars.pdf (accessed 22.08.2020).
} 
По мнению министра торговли ЕЭК В.О. Никишиной, в текущих реалиях мировой экономики и политики «органическим партнёром» для ЕАЭС по началу «развертывания» Большого Евразийского партнерства является Китай. «Сопряжение ЕАЭС и китайского проекта «Один пояс - один путь» станет не просто его важной частью, но, как мы надеемся, двигателем, «пилотным проектом» всей идеи в целом» ${ }^{4}$. Сегодня идею БЕП целесообразно рассматривать в измерениях содержательного наполнения концепции БЕП, а также продвижения данной инициативы среди международных партнеров и контактов по линии ЕАЭС.

В настоящее время официальной концепции формирования БЕП не существует. Представление об этой идее базируется на выступлениях и идеях Президента России В.В. Путина, которые развиваются Министром иностранных дел России С.В. Лавровым и рядом других официальных представителей российского руководства, экспертов и представителей деловых кругов.

Более того, с течением времени сама идея БЕП эволюционирует, начиная от «сети двусторонних и многосторонних торговых соглашений» до «сложения потенциалов различных интеграционных проектов» и «основы для формирования более гармоничного технологического и институционального мироустройства» с включением в него как азиатских, так и европейских стран.

Возвращаясь к идее БЕП на итоговой пленарной сессии XIII ежегодного заседания Международного дискуссионного клуба «Валдай» 27 октября 2016 г., В.В. Путин вновь отметил: «Россия выступает за гармонизацию региональных экономических форматов на основе принципов прозрачности и уважения интересов друг друга.

Именно так мы выстраиваем деятельность Евразийского экономического союза, ведем переговоры с нашими партнерами, в том числе о сопряжении с реализуемым Китаем проектом «Экономического пояса Шелкового пути». Надеемся, что это позволит сформировать Большое Евразийское партнерство... Для реализации этой идеи уже начат диалог в формате «пять плюс один» по соглашению о тор-

\footnotetext{
${ }^{4}$ Министр ЕЭК Вероника Никишина: «Большое Евразийское партнерство должно учитывать интересы всех игроков на пространстве Евразии»// Официальный сайт ЕЭК [Электронный pecypc]. URL: http://www.eurasiancommission.org/ru/nae/news/Pages/10-12-2019-5.aspx. (дата доступа: 22.08.2020).
} 
гово-экономическом сотрудничестве между всеми участниками данного процесса $\aleph^{5}$.

О необходимости создания Большого Евразийского партнерства между ЕАЭС и другими странами, включая Китай, Индию, Иран, Пакистан и партнеров по СНГ, В.В. Путин и другие российские представители говорили и на Восточном экономическом форуме во Владивостоке в сентябре 2016 г.

Наиболее развернутые концептуальные подходы изложены в научной статье академика РАН, д.э.н., профессора С.Ю. Глазьева «Большое Евразийское партнерство: созидая новый мир», где он отмечает, что «У России, ищущей альтернативные развилки экономической интеграции в рамках инициативы Президента В.В. Путина по созданию БЕП, есть опора на ключевого в АТР «азиатского тигра» в лице КНР. Ее председатель Си Цзиньпин в обоснование акселерации центростремительных тенденций между взаимно тяготеющими государствами континента на прошедшем во Владивостоке экономическом форуме терминологически и идеологически обозначил суть конструируемой интеграционной группы - Экономическое кольцо Северо-Восточной Азии. С трибуны ВЭФ - 2018 это было озвучено так: «Необходимо в приоритетном порядке повышать уровень взаимосвязанности транснациональной инфраструктуры, в сфере либерализации и упрощения торгово-инвестиционных процедур, содействовать ликвидности рынка, передвижению капиталов и технологиям, оптимизировать ресурсное обеспечение и индустриальную структуру, совместно строить открытую региональную экономику и сформировать экономическое кольцо Северо-Восточной Азии... Мы готовы вместе со всеми странами глубоко изучать возможности развития сотрудничества по другим многосторонним и субрегиональным форматам, чтобы запустить больше практических проектов на благо народов региона» [1, pp. 18-20]. При этом все участники процесса должны учитывать особенности социально-экономического и политического устройства евразийских государств, исходить из безусловного уважения национального суверенитета каждого государства, невмешатель-

\footnotetext{
${ }^{5}$ Владимир Путин принял участие в итоговой пленарной сессии XIII ежегодного заседания Международного дискуссионного клуба «Валдай». Тема заседания в этом году «Будущее начинается сегодня: контуры завтрашнего мира» // Официальный сайт Президента РФ [Электронный ресурс]. URL: http://kremlin.ru/events/president/news/53151 (дата доступа: 22.08.2020).
} 
ства в его внутренние дела, сохранения разнообразия хозяйственной и политической культуры как необходимого условия добросовестной конкуренции национальных юрисдикций и совместного развития на основе сочетания конкурентных преимуществ. БЕП должно формироваться на основе гибкой системы правовых норм, совместных проектов и институтов, которые учитывают интересы всех участников и исключительно добровольный характер сотрудничества.

Помимо официальных лиц тематику БЕП активно развивают деловые и экспертные круги. В частности, на страницах Медиагруппы «Звезда» 14 марта 2019 г. С.Ю. Глазьев, давая интервью «Большое евразийское партнерство создаст основу для формирования более гармоничного технологического и институционального мироустройства», подметил, что «Цель создания такого партнерства (БЕП) - долгосрочный мир и процветание Евразии. Для достижения этой цели необходимо решить некоторые задачи. А именно: создать преференциальные режимы торгово-экономического сотрудничества; развить материковую, транспортную, информационную и энергетическую инфраструктуры; научиться сочетать национальные планы развития с гармонизацией международной производственно-технологической кооперации и перейти к справедливой системе валютно-финансовых отношений. Также как и достигнуть прекращения существующих вооруженных конфликтов и не допускать новые» ${ }^{6}$.

По словам Министра иностранных дел России С. В. Лаврова в интервью китайской газете «Глобал Таймс» 28 мая 2020 г. «требуется совместный поиск новых точек роста, которые способны помочь преодолеть всеобщий спад. Вкладом в данную работу глобального масштаба может стать сложение потенциалов различных интеграционных проектов, которые реализуются на обширных евразийских пространствах. Именно на это ориентирована инициатива о формировании Большого Евразийского партнерства, основанного на принципах международного права и транспарентности, открытого для всех стран этого огромного континента, включая членов ЕврАзЭС, ШОС и АСЕАН. Ее планомерное осуществление не только укрепит позитивную экономическую взаимосвязанность, повысит конкурентоспособ-

\footnotetext{
${ }^{6}$ Сергей Глазьев: «Большое евразийское партнерство создаст основу для формирования более гармоничного технологического и институционального мироустройства» // Сетевое издание «Еженедельник «ЗВЕЗДА» [Электронный ресурс]. URL: https://zvezdaweekly.ru/news/t/2019313107-2Yqsz.html (дата доступа: 22.08.2020).
} 
ность всех участников, но и станет солидным заделом в деле построения пространства мира и стабильности от Лиссабона до Джакарты» ${ }^{7}$. Содержательно БЕП может представлять собой сеть ключевых региональных экономических объединений и крупнейших национальных экономик Евразии, связанных между собой гибкой системой международных правовых норм, транспортно-логистических, энергетических, телекоммуникационных и финансовых инфраструктур, совместных проектов и институтов, сочетающих национальные планы развития с гармонизацией международной производственнотехнологической кооперацией и стремящихся к продвижению справедливой системы валютно-финансовых отношений, взаимному открытию доступа на рынки товаров и услуг путем формирования преференциальных режимов торгово-экономического сотрудничества.

Целью БЕП является преображение Евразии в зону мира, процветания и сотрудничества. Ее результат предусматривает решение задач развития материковой транспортной, энергетической и информационной инфраструктуры, перехода к справедливой системе валютно-финансовых отношений, сочетания национальных планов развития и гармонизации международной производственно-технологической кооперации, взаимного открытия доступа на рынки товаров и услуг посредством создания преференциальных режимов торговоэкономического сотрудничества. Развитие концепции БЕП важно вести в контексте определения некого баланса между структурными экономическими проектами в регионе (китайская инициатива «Один пояс - один путь», Северный морской путь, Транссиб и др.) и возможными иными проектами, которые будут инициированы в будущем. К настоящему времени с учетом активного продвижения в экспертном сообществе тематики ОПОП, может складываться впечатление, что процесс формирования БЕП тесно связан с развитием инициативы «Один пояс - один путь». Такой подход не соответствует целям и универсальному характеру БЕП. Зачастую совмещение площадок Большого Евразийского партнерства и концепции сопряжения ЕАЭС инициативы «Один пояс - один путь» происходит и потому,

\footnotetext{
${ }^{7}$ Статья Министра иностранных дел Российской Федерации С. В. Лаврова о ситуации в мире в контексте пандемии коронавируса для китайской газеты «Глобал Таймс» // Официальный сайт МИД РФ. Москва, 28 мая 2020 года. [Электронный ресурс]. URL: https://www.mid.ru/foreign_policy/news/-/asset_publisher/cKNonkJE02Bw/content/id/4139447 (дата доступа: 22.08.2020).
} 
что курирование данных тем в России возложено на одно должностное лицо. Важно отметить, что Россия официально не присоединилась к проекту «Один пояс - один путь» и рассматривает данную инициативу в контексте интеграции с ЕАЭС. Идея строительства ЕАЭС и китайской инициативы «Один пояс - один путь» нашла отражение в подписанном в мае 2018 г. всеобъемлющем Соглашении о торгово-экономическом сотрудничестве между ЕАЭС и Китаем (вступило в силу 25 октября 2019 г.) и заключенном в июне 2019 г. Соглашении об обмене информацией о товарах и транспортных средствах международной перевозки, перемещаемых через таможенные границы ЕАЭС и КНР (пока не вступило в силу).

БЕП шире как географически, так и по содержанию. Концептуально идея Большого Евразийского партнерства предполагает охват всего континента, включая его азиатскую и европейскую части, в том числе развивая привычную европейцам идею создания единого экономического пространства от Лиссабона до Владивостока. Таким образом, идентификация инициативы «Один пояс - один путь» и идеи сопряжения строительства ЕАЭС и этой инициативы как стержня всего БЕП нецелесообразна, так как неполно отражает объективные экономические процессы, происходящие в Евразии. Отсюда возникает вывод, что уровень взаимодействия государств - членов Союза с глобальным экономическим локомотивом региона - Китаем - достаточно высок. Существует большая степень экономической ориентации Беларуси, Казахстана и Кыргызстана на Китай. На фоне конкретных финансово-экономических бонусов от сотрудничества с Китаем возможный эффект БЕП для отдельных государств - членов Союза пока не столь очевиден.

Выводы. Таким образом, с учетом специфики содержательного наполнения Большого Евразийского партнерства, возникает вопрос о возможности четкого формулирования подходов к архитектуре данной идеи, а также роли ЕАЭС в этой системе. Основные выводы о притягательности данной идеи для международных партнеров должны базироваться на предметном и тщательном экспертном анализе. Как представляется, усилиями стран ЕАЭС ее в разумно приемлемый промежуток времени написать чрезвычайно проблематично. Очертания этой концепции, подготовленные Россией, могли бы стать первым шагом к публичному диалогу на эту тему, определяющий дальнейший диалог, обсуждаемых в широком формате. Разносторонние 
форматы взаимодействия государств Большого Евразийского партнерства при необходимости и существования запроса со стороны партнеров в Евразии могут быть осуществлены в соответствующих рамочных документах, однако на данном этапе времени говорить об этом рано.

\title{
Библиографические ссылки
}

1. Глазьев С.Ю. Большое евразийское партнерство: созидая новый мир // Евразийская интеграция: экономика, право, политика. 2019. №. 1 (27). С. 18-20.

2. Гляни М. Китайская инициатива «один пояс - один путь»: что может сделать «бренд» // Проблемы постсоветского пространства. 2017. № 4(1). С. 8-19.

3. Новиков Д.П. Большое евразийское партнерство: возможное региональное влияние и интересы России // Вестник международных организаций: образование, наука, новая экономика. 2018. Вып. 13. № 3. С. 82-86.

4. Nye J., Keohane R. Transnational Relations and World Politics: An Introduction // International organization. 1971. Вып. 25. № 3. С. 329-349.;

5. Waltz K. Theory of International Politics. New York: McGraw-Hill Higher Education.; Ikenberry, 2001

Дата поступления статьи: 17.11.2020.

Автор: Иванцов Алексей Васильевич - соискатель кафедры социальной политики и идеологии Академии управления при Президенте Республики Беларусь, aliaskei.ivantsou@yandex.ru

DOI: $10.33581 / 2311-947-2020-8-47-58$

\section{PROMOTION OF THE GREATER EURASIAN PARTNERSHIP WITHIN THE FRAMEWORK OF THE EAEU: PROBLEMS AND PROSPECTS}

\section{A. V.IVANTSOV}

Academy of Public Administration under the President of the Republic of Belarus, Minsk, Republic of Belarus

\begin{abstract}
This article examines the current state and future prospects of integration associations, as well as the formats of multilateral economic cooperation in terms of implementing the Greater Eurasian partnership initiative. The author analyzes the experience of the largest multilateral formats in Eurasia - the Comprehensive regional economic partnership (RCEP), the Chinese initiative "one belt, one road", the Eurasian economic Union, etc.
\end{abstract}


It is concluded that in the current state of the economic sphere of Greater Eurasia, there is an institutional overload caused by the existence of a number of parallel developing integration projects and mechanisms of economic cooperation. Strengthening the EEU as the institutional center of Greater Eurasia can become the basis for the formation of a balanced regulatory mega-space. However, the combined economic potential of the EAEU member States does not allow the Union to be the largest economic pole and the leading center for the development of multilateral institutions in Greater Eurasia.

It is assumed that the solution in this situation could be the development of a Comprehensive Eurasian partnership towards the integration of the EAEU and the EEU - the largest format for developing rules for international economic cooperation in Asia, as well as formulating specific proposals for building a system of mutually beneficial relations between the largest players in Eurasia, in which all interested States will be involved on mutually beneficial terms to strengthen international cooperation.

Keywords: Great Eurasian partnership; RCEP; EEU; Eurasia; integration; "one belt, one road"; Union; EBSR; SCO.

For citations: Ivantsov, A.V. (2020). Promotion of the Greater Eurasian partnership within the framework of the EAEU: problems and prospects. In: Actual problems of international relations and global development: collection of scientific papers. Minsk, Vol. 8, p. 47-57. https://doi.org/10.33581/2311-947-2020-8-47-58

\section{References}

1. Glazev, S.Y. (2019). Bol'shoye evraziyskoye partnerstvo: sozidaya novyi mir. [The Great Eurasian Partnership: Building a New World]. In: Eurasian Integration: Economics, Law, Politics. No. 1 (27), p. 18-20. (In Russ.).

2. Glyants, M. (2017). Kitaiskaya initsiativa «odin poyas - odin put'»: chto mozhet sdelat' «brend» [China's Belt and Road Initiative: What a Brand Can Do]. In: Problems of the post-Soviet space. No 4 (1), p. 8-19. (In Russ.).

3. Novikov, D.P. Bol'shoye yevraziyskoye partnerstvo: vozmozhnoye vliyaniye i interesy Rossii [Great Eurasian Partnership: Potential Regional Influence and Interests of Russia]. In: Bulletin of International Organizations: Education, Science, New Economy. Vol. 13, net. 3, 2018, p. 82-96. (In Russ.).

4. Nye, J., Keohane, R. (1971). Transnational Relations and World Politics: An Introduction. In: International organization. Vol. 25, no 3, pp. 329-349.;

5. Waltz, K. (1979) Theory of International Politics. New York: McGraw-Hill Higher Education.; Ikenberry, 2001.

Received: 17.11.2020.

About author: Ivantsov Aleksei Vasilyevich - applicant of Department of social policy and ideology Academy of Public Administration under the President of the Republic of Belarus, aliaskei.ivantsou@yandex.ru. 